\title{
Results of clinical trials with diuretics in heart failure
}

J R Hampton

The introduction of the loop diuretics frusemide and ethacrynic acid in the early 1960s had a dramatic effect on medical practice. Until then patients with heart failure were treated with digoxin, thiazides, or intramuscular injections of a mercurial such as mersalyl. Heart failure had been considered a terminal condition, but the new diureticsactive both by injection and by tabletsuddenly allowed the most amazing resolution of fluid retention. It was obvious that they worked, and little in the way of clinical trials was needed for the new drugs to be welcomed into standard practice.

It is perhaps important to remember that in the early 1960s not only was there a lack of alternatives to loop diuretics, but the pathophysiology of heart failure was not well understood. Bedside haemodynamic monitoring was not possible, and even electrocardiographic monitoring was in its infancy in most hospitals. No one appreciated the importance of vasoconstriction in heart failure, and it was not possible to measure any of the hormonal responses associated with it. The introduction of loop diuretics therefore was not, could not be, and did not need to be, accompanied by the intense investigations considered essential for the approval of any new drug today. Consequently we are short of information about the effect of diuretics, both in the short and the long term, and because they are now standard cheap drugs it is unlikely that money will be forthcoming that will permit extensive research programmes.

The advent of loop diuretics stands in sharp contrast with that of the angiotensin converting enzyme (ACE) inhibitors. The ACE inhibitors were introduced when large clinical trials were a prerequisite for licensing, and further competition between different pharmaceutical companies trying to market ACE inhibitors with minor differences led to a plethora of trials. These have elucidated the role of ACE inhibitors in the treatment of symptoms and the prevention of death, and have considerably advanced our knowledge of the pathophysiology of heart failure.

Division of Cardiovascular Medicine, Queen's Medical Centre, Nottingham J R Hampton Correspondence to: Professor J R Hampton, Division of Cardiovascular Medicine, Queen's Medical Centre, Nottingham NG7 2UH. with an increase in ventricular arrhythmias.

Despite these apparent disadvantages, loop diuretics are very widely used. We have surveyed this in Nottinghamshire, a county with a population of just over one million, with the prescribing analysis and cost (PACT) data from the Prescription Pricing Authority of the National Health Service. These data provide information about the numbers of prescriptions issued, not about individual patients, so it is necessary to use sampling techniques to interpret PACT results for epidemiological purposes.

In the year beginning 1 April 1991 prescriptions were issued in Nottinghamshire for a total of $382726600 \mathrm{mg}$ of frusemide (the equivalent of 9.5 million $40 \mathrm{mg}$ tablets). This equates to $1048566 \mathrm{mg}$ or 26214 tablets (40 mg daily). In a sample of about 400 patients treated with frusemide in general practice, the daily dose ranged from 20-1000 $\mathrm{mg}$ (median, $40 \mathrm{mg}$; and mean, $60 \mathrm{mg}$ ). Also, there were about 20000 prescriptions for bumetanide.

The survey of individual patients given loop diuretics showed that just over half had unequivocal evidence of heart failure: in the rest the diuretic was prescribed either for hypertension or ankle swelling of uncertain cause. We have used these data to estimate prevalence of heart failure in Nottinghamshire, and for all ages this seems to be $10-15 / 1000$, depending on the assumptions made. For our present purposes, however, the important thing to note is that in a population of one million, between 20000 and 30000 patients are being treated with loop diuretics. ${ }^{2}$

\section{Diuretics and pathophysiology of heart failure}

It is important to remember that by the time overt symptoms and signs of heart failure have appeared, the physiological responses to cardiac dysfunction have been overwhelmed. ${ }^{3}$ The clinical manifestation of heart failure is a syndrome resulting from changes in the whole of the circulatory system. At the stage before overt symptoms are present, cardiac damage causes an increase in wall tension and by the Frank-Starling mechanism contractility in the non-damaged heart muscle is increased; the sympathetic system is activated and $\beta$ adrenergic receptors in the non-injured myocardium also increase contraction. Sympathetic stimulation also causes peripheral arteriolar and venous constriction that maintain pressure but make the problem worse so far as the myocardium is concerned, but other factors reduce sympathetic stimulation: atrial stretch releases atrial natriuretic 
peptide, which is a vasodilator, and also inhibits noradrenaline release, and eventually a new balance is achieved. Cardiac hypertrophy eventually overcomes some of the fundamental cardiac problems. Once clinical symptoms and signs of heart failure have appeared, systemic perfusion is maintained by peripheral vasoconstriction and sodium retention: peripheral vasoconstriction is due sequentially to activation of the sympathetic, renin-angiotensin, and vasopressin mechanisms, and sodium retention results from renin-angiotensin activation and loss of the atrial natriuretic peptide mechanism.

Asymptomatic left ventricular dysfunction and the clinical syndrome of overt heart failure therefore involve a very different physiological state even though there is obviously a considerable overlap between the two conditions. There is no reason to suppose that both can be improved by the same drugs.

Studies of the neuroendocrine system in untreated heart failure have shown that at least in the early stage, plasma noradrenaline and atrial natriuretic peptide are high, but plasma renin activity and aldosterone are normal. ${ }^{45}$ These are increased after diuretic treatment.

The effects of diuretics on the circulation are much more complex than simply those resulting from sodium and water excretion through the kidney and from the activation of the renin-angiotensin system, which tend to counter this effect. The beneficial effects of diuretics occur much more quickly than either of these, and the initial effect of intravenous frusemide is undoubtedly venodilatation. Frusemide causes a rapid fall in right atrial and pulmonary artery diastolic pressure accompanied at least at first by a fall in cardiac output; the increase in sodium excretion follows later. ${ }^{67}$ It has been suggested that diuretics also cause arteriolar dilatation. ${ }^{8}$ Few long-term studies of the haemodynamic effects of diuretics have been performed, but the classic findings of Stampfer et al 25 years ago showed that when oedematous patients were treated with chlorothiazide until they were "dry" there was a fall in right atrial pressures and in the pulmonary capillary wedge pressure. ${ }^{9}$ Again, there was a fall in cardiac output but the patients' exercise times were improved (table 1).

Table 1 Haemodynamic effects of chlorothiazide (Stampfer et al 1986) ${ }^{9}$

\begin{tabular}{lcc}
\hline 15 Patients in NYHA II or III & $\begin{array}{l}\text { Before treatment } \\
\text { (wet) }\end{array}$ & $\begin{array}{l}\text { After treatment } \\
\text { (dry) }\end{array}$ \\
\hline Weight (kg) & $66 \cdot 0$ & $62 \cdot 0$ \\
Mean RAP (mm Hg) & 9 & 4 \\
RVEDP (mm Hg) & 11 & 6 \\
Mean PAP (mm Hg) & 41 & 26 \\
Mean PCWP (mm Hg) & 24 & 13 \\
CO (1/min) & $4 \cdot 5$ & $3 \cdot 6$ \\
Mean exercise times (min) & $7 \cdot 5$ & 9
\end{tabular}

RAP, right atrial pressure; RVEDP, right ventricular end diastolic pressure; PAP, pulmonary artery pressure; PCWP pulmonary capillary wedge pressure; $\mathrm{CO}$, cardiac output.

\section{Diuretics for the treatment of}

symptomatic heart failure

Loop diuretics activate the renin-angiotensin system and so cause more vasoconstriction, and at least in theory the resulting rise of aldosterone may cause an increase in sodium retention. Theoretically this may limit the efficacy of the diuretic, ${ }^{10}$ but clinical improvement can often be achieved simply by increasing diuretic dose. Kiyingi et al showed that to add a different class of diuretic such as metolazone can improve symptoms and enhance sodium excretion in oedematous patients with New York Heart Association (NYHA) class IV heart failure who are already on huge doses of frusemide. ${ }^{11}$ Seventeen such patients who were on oral frusemide (200-500 mg daily) plus intravenous frusemide (120 mg daily) as well as digoxin and ACE inhibitors were given metolazone. Twelve of these extremely ill patients improved to NYHA class II or III, with a mean weight loss of $8.3 \mathrm{~kg}$, and the intravenous frusemide was discontinued.

\section{Diuretics combined with ACE inhibitors in symptomatic heart failure}

The first placebo controlled trial that showed a beneficial effect on exercise time when captopril was added to diuretics was published in $1982 .{ }^{12}$ Since then several studies have confirmed this effect. ${ }^{13-15}$

As ACE inhibitors reverse vasoconstriction in heart failure and reduce aldosterone mediated sodium retention, they should be ideal drugs to use as monotherapy in heart failure. It is therefore surprising that there is little or no evidence to suggest that ACE inhibitors are effective for the treatment of clinical heart failure without diuretics being given concomitantly. In a series of 14 patients with documented left ventricular dysfunction whose symptoms were controlled by frusemide ( 40 $\mathrm{mg}$ daily), the diuretic was withdrawn and was replaced by captopril. ${ }^{16}$ Four patients, who were among those who had the most severe heart failure originally, developed pulmonary oedema when the treatment was changed.

The addition of ACE inhibitors does not necessarily reduce diuretic requirements. Odemuyiwa et al studied 16 non-oedematous patients with heart failure who were being treated with at least $80 \mathrm{mg}$ of frusemide daily. ${ }^{17}$ Captopril was added and at the same time the diuretic dose was halved. The three patients who were severely symptomatic despite being free of oedema all deteriorated and needed the original dose of diuretic. Five of the 13 initially in heart failure NYHA class II or III also needed an increase in diuretic treatment up to the original dose, whereas one remained unchanged and seven improved without any increase in diuretics.

Clearly we need some large comparative trials directly comparing ACE inhibitors and diuretics for the treatment of mild and moderate heart failure. It has become virtually 
impossible to find untreated patients who could be included in such a study, and it might well be argued that such a trial would be unethical. We therefore lack, and are likely to lack, good evidence of the effect of ACE inhibitors alone in symptomatic patients.

In combination with diuretics, digoxin has been shown to have a similar effect to captopril on exercise time and on the need for increased treatment for heart failure. ${ }^{18}$ Most other heart failure drugs also add to the effect of diuretics so there does not seem to be anything specific about the relation between diuretics and ACE inhibitors.

A comparison of the addition of captopril to diuretic treatment with an increased dose of the diuretic also suggested that there was little to choose between these changes in treatment. ${ }^{19}$ Ten patients with moderate (NYHA class II or III) heart failure who were symptomatic despite treatment with frusemide ( $40 \mathrm{mg}$ daily) were randomised to receive either an extra 40 and then an extra 80 $\mathrm{mg}$ of frusemide, or alternatively captopril (25 $\mathrm{mg}$ and then $50 \mathrm{mg}$ three times daily). Both treatments improved symptom limited exercise tolerance; higher dose frusemide had a more favourable effect although the difference from captopril was not significant. Both treatments reduced perceived exertion during submaximal exercise to a similar extent and improved symptoms as assessed by questionnaire. Both additional frusemide and the introduction of captopril reduced (but neither fully corrected) the peripheral vasoconstriction characteristic of heart failure. This was a small study and a much larger study of the same treatments, but with a parallel-group design, is clearly needed. Unfortunately the proved benefits of ACE inhibitors on survival make such a study virtually impossible to perform.

It therefore seems fairly clear that diuretics are necessary to relieve symptoms; the addition of an ACE inhibitor undoubtedly improves symptoms, but not definitely more so than would an increase in diuretics or the addition of some other agent (such as digoxin) to diuretic treatment. But the value of diuretics for survival rather than symptomatic relief in patients with heart failure is entirely unknown, for no trial of diuretic treatment with survival as an end point has ever-or probably, will ever-be conducted.

\section{Diuretics for improved survival in heart failure}

Natural history studies do not help much to elucidate the long-term effect of diuretics. ${ }^{20}$ Any variable that would be expected to indicate severe as opposed to mild cardiac disease indicates a poor prognosis, ${ }^{21}$ but the dose of diuretic used has variously been claimed to be of little ${ }^{21}$ or of considerable ${ }^{22}$ prognostic value.

Similarly, the trials of drugs other than diuretics that lengthen survival in patients with symptomatic heart failure do not clarify the role of diuretics, for without exception each trial expected the patients to be on optimal diuretic treatment before randomisation to the experimental drug. This applies to trials involving digoxin, ${ }^{23-25}$ milrinone, ${ }^{23} 26$ hydralazine plus nitrate, ${ }^{27}$ and xamoterol, ${ }^{24}{ }^{28}$ as well as the ACE inhibitors. ${ }^{29-31}$ In the original ACE inhibitor survival trial, the cooperative north Scandinavian enalapril survival study (CONSENSUS), the patients were being treated with a mean dose of $200 \mathrm{mg}$ of frusemide daily. ${ }^{30}$ The ACE inhibitors seemed effective in all these trials whatever the dose of diuretic; in the only ACE inhibitor trial in which active treatment failed to improve survival (the CONSENSUS II study of enalapril in patients with acute myocardial infarction) the fatality rate was essentially the same in the active placebo groups whether or not diuretics were used. ${ }^{32}$

Although there have been no placebo controlled trials of diuretics with a survival end point in patients with heart failure, there has been a study in which the effects of frusemide, captopril, and placebo were compared for their ability to prevent left ventricular dilatation after myocardial infarction. ${ }^{33}$ The captopril group showed no change in left ventricular end diastolic volume and in these patients ejection fraction was increased; in the frusemide and placebo groups the ventricular volumes increased and the ejection fraction was reduced. If we could be sure that left ventricular dilatation is an accurate surrogate for survival this would certainly suggest that frusemide treatment is not ideal, but there is no substitute for a true survival study.

\section{Unwanted effects of diuretic treatment}

Possible adverse effects of diuretics have been studied in more detail during the treatment of hypertension than in patients treated for heart failure, although in these two situations the risks and benefits of treatment are probably quite different. Furthermore, the lower dose of diuretics now used in hypertension probably does not activate the renin-angiotensin system to any great extent. ${ }^{34}$

In the Medical Research Council hypertension trial diuretics increased ventricular extrasystoles but nevertheless reduced fatality, ${ }^{35}$ so it seems unlikely that diuretic induced arrhythmias are important. The overall effect of diuretics on risk factors are probably of little clinical importance ${ }^{36}$ - for example, in the second MRC trial $^{37}$ the mean plasma cholesterol concentration increased by $4 \mathrm{mg} / \mathrm{dl}$ in both the diuretic treated and the placebo groupsand in the European Working Party on Hypertension in the Elderly (EWPHE) trial the mean cholesterol concentration fell by an equal amount in those given diuretics and those given placebo. ${ }^{38}$ The first MRC trial gave a good quantitative estimate of the incidence of side effects that might be expected from diuretics (table 2) ${ }^{39}$ : these figures are probably relevant to patients with heart failure because a relatively high dose of diuretics was used. 
Table 2 Problems causing withdrawal from treatment in the MRC study, expressed as rate per 1000 patient-years of treatment ${ }^{39}$

\begin{tabular}{lccl}
\hline Problem & BZF & Propranolol & Placebo \\
\hline Impaired glucose tolerance & $9 \cdot 38^{\star}$ & 1.65 & $2 \cdot 51$ \\
Gout & $11 \cdot 23^{\star}$ & $2 \cdot 56$ & $1 \cdot 03$ \\
Impotence & $19 \cdot 58^{\star}$ & $5 \cdot 48^{\star}$ & $0 \cdot 89$ \\
Lethargy & $6 \cdot 91^{\star}$ & $10 \cdot 23^{\star}$ & $0 \cdot 20$ \\
Raynaud's disease & 0 & $5 \cdot 48^{\star}$ & $0 \cdot 19$ \\
Dyspnoea & 0 & $5 \cdot 48^{\star}$ & $0 \cdot 15$ \\
\hline
\end{tabular}

$\star \mathbf{P}<0.05$ (bendrofluazide).

\section{BENEFITS OF DIURETICS IN THE HYPERTENSION} TRIALS

The overall result of the many trials in which diuretics have been compared with placebo to treat hypertension is that active treatment is beneficial, ${ }^{40}$ particularly in the reduction of stroke. Although this can be taken to mean more that high blood pressure is harmful than that diuretics are good, some information about the actual benefit of diuretics can be inferred from the blood pressure trials in which diuretics were compared with $\beta$ blockers. In three of the four trials (table 3 ) diuretics and $\beta$ blockers were associated with essentially the same proportions of vascular events: in the second MRC trial diuretic treatment led to less vascular deaths and strokes than treatment with a $\beta$ blocker, ${ }^{37} 394142$ although the difference was not statistically significant; there were, however, significantly fewer myocardial infarctions in the diuretic group.

The use of diuretics was blamed by some for the failure of special intervention in the multiple risk factor intervention trial (MRFIT) to reduce fatality in healthy patients considered to be at high risk of cardiovascular disease. ${ }^{43}$ Subgroup analysis showed that patients who started with an abnormal electrocardiogram and who were hypertensiveand who therefore were probably treated with diuretics-had an increased fatality rate. Special intervention was, however, also associated with an increased fatality in the subgroup of non-hypertensive patients with normal electrocardiograms, and overall it seems likely that these differences between groups occurred by chance. This view is supported by the results of the systolic hypertension in the elderly programme (STOP) ${ }^{44}$; here the relative risk of fatal plus non-fatal myocardial infarction in the actively (diuretic) treated

Table 3 Events in the trials comparing diuretics and $\beta$ blockers (\% of randomised patients)

\begin{tabular}{|c|c|c|}
\hline & Diuretics & $\beta$ Blockers \\
\hline \multicolumn{3}{|l|}{ Vascular deaths: } \\
\hline $\mathrm{MRC}^{39}$ & 1.6 & 1.5 \\
\hline IPPPSH ${ }^{41}$ & $1 \cdot 8$ & 1.4 \\
\hline HAPPHY ${ }^{42}$ & 1.8 & 1.7 \\
\hline$M R C-2^{37}$ & $6 \cdot 1$ & $8 \cdot 6$ \\
\hline \multicolumn{3}{|l|}{ Stroke: } \\
\hline $\mathrm{MRC}^{39}$ & 0.4 & 0.9 \\
\hline IPPPSH & $1 \cdot 4$ & 1.4 \\
\hline HAPPHY & $1 \cdot 2$ & 1.0 \\
\hline$M R C-2^{37}$ & $4 \cdot 2$ & $5 \cdot 1$ \\
\hline \multicolumn{3}{|l|}{ Myocardial infarction: } \\
\hline MRC $^{39}$ & $1 \cdot 3$ & 1.5 \\
\hline IPPPSH & 1.8 & 1.4 \\
\hline HAPPHY & $1 \cdot 8$ & $1 \cdot 7$ \\
\hline MRC- $2^{37}$ & $4 \cdot 4$ & $7 \cdot 2^{\star}$ \\
\hline
\end{tabular}

group compared with placebo was 0.83 in patients with normal electrocardiograms (non-significant), and 0.69 in those with abnormal electrocardiograms (significant).

The final evidence favouring use of diuretics in hypertension is that in hypertensive patients diuretic treatment, probably like any other successful pressure reduction treatment, seems to reverse left ventricular hypertrophy. ${ }^{45}$

There is certainly nothing in the vast hypertension experience to make us worry about the use of diuretics in general. Evidence for the effects of diuretics in hypertension can only be considered circumstantial as far as heart failure is concerned, but if what matters in hypertension is the reduction of blood pressure rather than the way this is achieved, the same could well be true of the treatment of heart failure.

\section{Conclusions}

Diuretics are at present the first line drugs for the treatment of fluid retention due to heart failure, and there are good physiological and clinical reasons why this should continue. Perhaps because they were introduced before the days of large clinical trials with mortality end points we do not know their effect on survival: however, the lack of an alternative to diuretics for symptom control then and now makes it very difficult to see how a mortality end point trial could be designed. Although diuretics activate the neuroendocrine system and cause a variety of biochemical changes that are theoretically undesirable, large controlled trials of hypertension suggest that these were of little clinical importance. There is no reason why diuretics should fall into disfavour.

1 Clarke KW, Gray D, Hampton JR. The prevalence of heart failure estimated from prescription data [abstract] heart failure estimated from presc

2 Clarke, KW, Gray D, Hampton JR. Defined daily doses: an insensitive tool in the determination of the prevalence of heart disease. Pharmaceutical fournal 1994;252: 334-5.

3 Packer $M$. Pathophysiology of chronic heart failure. Lance 1992;340:88-92

4 Bayliss J, Norell $M$, Canepa-Anson R, Sutton G, PooleWilson P. Untreated heart failure: clinical and neuroendocrine effects of introducing diuretics. Br Heart $f$ 1987;57:17-22.

5 Remes J, Tikkanen I, Fyhrquist F, Pyorala K Neuroendocrine activity in untreated heart failure. $B$ Heart $\mathcal{F}$ 1991;65:249-55.

6 Larsen FF. Haemodynamic effects of high or low doses of furosemide in acute myocardial infarction. Eur Heart $f$ furosemide in

7 Ikro 3 :125-31. $W$, Espiner EA Nicholls MG Haemodynamic and hormone responses to acute and Haemodynamic and hormone responses to acute and chronic frusemide ther

8 Wilson JR, Reichek N, Dunkman WB, Goldberg S. Effect of diuresis on the performance of the failing left ventricle in man. $A m \mathcal{F} M e d 1981 ; 70: 234-9$.

9 Stampfer M, Epstein SE, Beiser GD, Braunwald E. Hemodynamic effects of diuresis at rest and during intense upright exercise in patients with impaired cardiac function. Circulation 1968;37:900-11.

10 Packer $M$. Treatment of chronic heart failure. Lance 1992;340:92-5.

11 Kiyingi A, Field MJ, Pawsey CC, Yiannikas J, Lawrence JR, Arter WJ. Metolazone in treatment of severe refractory congestive cardiac failure. Lancet 1990;335:29-31.

12 Cowley AJ, Rowley JM, Stainer KL, Hampton JR Captopril therapy for heart failure. Lancet 1982;ii 730-2

13 Kramer BL, Massie BM, Topic N. Controlled trial of captopril in chronic heart failure: a rest and exercise hemodynamic study. Circulation 1983;67:807-15. 
14 Captopril Multicenter Research Group. A placebo-controlled trial of captopril in refractory chronic congestive heart failure. I Am Coll Cardiol 1983;2:755-63.

15 Cleland JGF, Dargie HJ, Hodsman GP, et al. Captopril in heart failure. A double blind controlled trial. Br Heart $f$ 1984;52:530-5.

16 Richardson A, Bayliss J, Scriven AJ, Parameshwar J Poole-Wilson PA, Sutton GC. Double-blind comparison of captopril alone against frusemide plus amiloride in mild heart failure. Lancet 1987;ii:709-11.

17 Odemuyiwa O, Gilmartin J, Kenny D, Hall RJC Captopril and the diuretic requirements in moderate and severe chronic heart failure. Eur Heart $f$ 1989;10: 586-90.

18 The Captopril-Digoxin Multicenter Research Group Comparative effects of therapy with captopril and digoxin in patients with mild to moderate heart failure ЭAMA 1988;259:539-44.

19 Cowley AJ, Stainer K, Wynne RD, Rowley JM, Hampton JR. Symptomatic assessment of patients with heart failure: double-blind comparison of increasing doses of diuretics and captopril in moderate heart failure. Lancet 1986;ii:770-2.

20 Kannel WB. Epidemiology and prevention of cardiac failure: Framingham Study insights. Eur Heart $f 1987$; failure: Framing

21 Cleland JGF, Dargie HJ, Ford I. Mortality in heart failure: clinical variables of prognostic value. Br Hear $\mathcal{f}$ 1987;58:572-82.

22 Cowley AJ. Studies of patients with heart failure. Nottingham: University of Nottingham, 1988. (DM Thesis).

23 DiBianco $R$, Shabetai $R$, Kostuk W, et al. For the Milrinone Multicenter Trial Group. A comparison of oral milrinone, digoxin and their combination in the treatment of patients with chronic heart failure. $N$ Engl $f$ Med 1989;320:677-83.

24 The German and Austrian Xamoterol Study Group. Double-blind placebo-controlled comparison of digoxin and xamoterol in chronic heart failure. Lancet 1988;i: 489-93.

25 Davies RF, Beanlands DS, Nadeau C, et al. For the Canadian Enalapril versus Digoxin Study Group. Canadian Enalapril versus Digoxin Study Group. Enalapril versus digoxin in patients with congestive heart failure: $A$

26 Packer M, Carver JR, Rodeheffer RJ, et al. For the PROMISE Study Research Group. Effect of ora Milrinone on mortality in severe chronic heart failure. $N$ Engl f Med 1991;325:1468-75.

27 Veterans administration cooperative study on vasodilato therapy of heart failure: influence of prerandomization variables on the reduction of mortality by treatment with hydralazine and isosorbide dinitrate. Circulation 1987;75(suppl IV):49-54.

28 The Xamoterol in Severe Heart Failure Study Group. Xamoterol in severe heart failure. Lancet 1990;336:1-6.

29 Cohn JN, Johnson G, Ziesche S, Cobb F, et al. A comparison of enalapril with hydralazine-isosorbide dinitrate in treatment of chronic congestive heart failure. $N$ Engl $\mathcal{f}$ Med 1991;325:303-10.

30 The CONSENSUS Trial Study Group. Effects of enalapril on mortality in severe congestive heart failure. Results of the cooperative north Scandinavian enalapril survival study (CONSENSUS). N Engl f Med 1987;316: 1429-35.

31 Kleber FX Niemoller L, Doering W. Impact of converting enzyme inhibition on progression of chronic heart failenzyme inhibition on progression of chronic heart failure: results of the Munich

32 Results of the cooperative north Scandinavian enalapril survival study II (CONSENSUS II). Effects of the early administration of enalapril on mortality in patients with acute myocardial infarction. $N$ Engl $f$ Med 1992;327 678-84

33 Sharpe N, Murphy J, Smith H, Hannan S. Treatment of patients with symptomless left ventricular dysfunction after myocardial infarction. Lancet 1988; i:255-9.

34 Burnier M, Brunner HR. Neurohormonal consequences of diuretics in different cardiovascular syndromes. Eur Heart 7 1992;13(suppl G):28-33.

35 Medical Research Council Working Party on mild to moderate hypertension. Ventricular extrasystoles during thiazide treatment: substudy of MRC mild hypertension azide treatment: substudy of

36 trial. $B M F$ 1983;287:1249-53. Heart $₹$ 1992;13(suppl G):72-80.

37 MRC Working Party. Medical Research Council trial of treatment of hypertension in older adults: principal results. $B M \mathcal{F}$ 1992;304:405-12.

38 Mortality and morbidity results from the European Working Party on high blood pressure in the elderly trial (EWPHE) trial. Lancet 1985;i:1349-54.

39 MRC trial of treatment of mild hypertension: principal results. Medical Research Council Working Party. BM 1985;291:97-104.

40 Hampton JR. Comparative efficacy of diuretics: benefit versus risk: results of clinical trials. Eur Heart $\mathcal{J}$ 1992;13:(suppl G):85-91.

41 The IPPPSH Collaborative Group. Cardiovascular risk factors in a randomised trial of treatment based on the $\beta$ blocker experience: the international prospective primary prevention study in hypertension (IPPPSH). 7 mary prevention study

42 Heart Attack Primary Prevention in Hypertension Trial Research Group. $\beta$ Blockers versus diuretics in hypertensive men: main results from the HAPPHY trial. Hypertension 1987;5:561-71.

43 Multiple Risk Factor Intervention Trial Research Group. (MRFIT). Multiple risk factor intervention trial. Risk factor changes and mortality results. $\mathscr{F} A M A$ 1982;248:1465-77.

44 Dahglof B, Lindholm L, Hansson L, et al. Morbidity and mortality in the Swedish trial in old patients with hypertension (STOP-Hypertension). Lancet 1991;338:1281-4.

45 Massie BM. Effect of diuretic therapy on hypertensive left ventricular hypertrophy. Eur Heart f 1992;13(suppl G): $53-60$. 